\title{
Risk Factors for Lower-Extremity Injuries Among Contemporary Dance Students
}

\author{
Christine van Seters, MD, ${ }^{\star} \dagger$ Rogier M. van Rijn, PhD, ${ }^{*}$ Marienke van Middelkoop, PhD, $†$ and \\ Janine $\mathrm{H}$. Stubbe, $\mathrm{PhD}^{\star} \neq$
}

\begin{abstract}
Objective: To determine whether student characteristics, lower-extremity kinematics, and strength are risk factors for sustaining lower-extremity injuries in preprofessional contemporary dancers. Design: Prospective cohort study. Setting: Codarts University of the Arts. Patients: Forty-five first-year students of Bachelor Dance and Bachelor Dance Teacher. Assessment of Risk Factors: At the beginning of the academic year, the injury history (only lower-extremity) and student characteristics (age, sex, educational program) were assessed using a questionnaire. Besides, lower-extremity kinematics [single-leg squat (SLS)], strength (countermovement jump) and height and weight (body mass index) were measured during a physical performance test. Main Outcome Measures: Substantial lower-extremity injuries during the academic year were defined as any problems leading to moderate or severe reductions in training volume or in performance, or complete inability to participate in dance at least once during follow-up as measured with the Oslo Sports Trauma Research Center (OSTRC) Questionnaire on Health Problems. Injuries were recorded on a monthly basis using a questionnaire. Analyses on leg-level were performed using generalized estimating equations to test the associations between substantial lower-extremity injuries and potential risk factors. Results: The 1-year incidence of lower-extremity injuries was $82.2 \%$. Of these, $51.4 \%$ was a substantial lower-extremity injury. Multivariate analyses identified that ankle dorsiflexion during the SLS (OR 1.25; 95\% confidence interval, 1.03-1.52) was a risk factor for a substantial lower-extremity injury. Conclusions: The findings indicate that contemporary dance students are at high risk for lower-extremity injuries. Therefore, the identified risk factor (ankle dorsiflexion) should be considered for prevention purposes.
\end{abstract}

Key Words: dance, preprofessional, injury, lower extremity, risk factors, prospective cohort study

(Clin J Sport Med 2020;30:60-66)

\section{INTRODUCTION}

Contemporary dance students participate in long hours of class, rehearsal, and performance. ${ }^{1}$ Training consists of repetitive movements ${ }^{2,3}$ exceeding anatomical limitations ${ }^{4}$ and demanding versatility. ${ }^{5}$ These demands make a dance student at high risk for injuries. ${ }^{6}$ The yearly overall risk of injuries in preprofessional contemporary dancers is more than $60 \%,{ }^{6-8}$ with dancers returning to full dancing after a mean of 57 days \pm 91 days (males) and 41 days \pm 55 days (females) as a consequence of an injury. ${ }^{9}$ Most predominant musculoskeletal injuries seen in dancers are lower-extremity injuries. ${ }^{1,7,8,10,11}$ The highest injury rates are found for the ankle/foot $(20.5 \%-28.0 \%)$, the knee $(16.0 \%-21.4 \%)$ and the lower back $(13.4 \%-17.0 \%) .^{7-9}$ The 3 most common diagnoses reported in professional contemporary dancers were muscle strains $(28 \%)$, ligament sprains $(23 \%)$, and chronic processes such as tendonitis and bursitis $(21 \%))^{9}$

In athletes, the dynamic position of the knee is considered to be a risk factor for injuries of the lower-extremity. ${ }^{12}$ For

Submitted for publication March 23, 2017; accepted August 31, 2017.

From the ${ }^{*}$ Codarts, University of the Arts, Rotterdam, the Netherlands; ${ }^{\dagger}$ Department of General Practice, Erasmus MC University Medical Center, Rotterdam, the Netherlands; and ${ }^{\ddagger}$ Amsterdam University of Applied Sciences, Centre for Applied Research in Sports and Nutrition, Amsterdam, the Netherlands.

The authors report no conflicts of interest.

Corresponding Author: Rogier M. van Rijn, PhD, Codarts, University of the Arts, Kruisplein 26, 3012 CC Rotterdam, the Netherlands (rmvanrijn@codarts.nl).

Copyright $\odot 2017$ Wolters Kluwer Health, Inc. All rights reserved.

http://dx.doi.org/10.1097/JSM.0000000000000533 instance, external rotation and abduction of the knee during landing or squatting tasks are known risk factors for anterior cruciate ligament lesions and patellofemoral pain (PFP) in the general athletic population. ${ }^{13-15}$ In addition, cross-sectional studies have shown that patients with PFP have more hip adduction, knee flexion, knee medio-lateral displacement, and peak ipsilateral trunk lean during these tasks than healthy people. ${ }^{16,17}$ Kenny et al (2016) performed a systematic review to identify and evaluate the evidence examining risk factors for musculoskeletal injuries in dancers. Similar to what has previously been found in athletes, Kenny et $\mathrm{al}^{1}$ stated that there are indications that lower-leg alignment is associated with dance injuries. ${ }^{1}$ In 2 cross-sectional studies with (pre-) professional contemporary- and ballet dancers, a difference in lower-extremity strength was found between injured and noninjured dancers, with a lower strength among injured dancers. ${ }^{18,19}$ These findings suggest that the dynamic position of the knee and lower-extremity strength may be risk factors for lower-extremity injuries in dancers.

Considering the high frequency of lower-extremity injuries in dancers and the corresponding high absenteeism (ie, classes, rehearsals, and performances) as a result of injuries, insight in factors predicting substantial injuries would enable us to enhance the prevention of dance-related injuries. Therefore, the aim of this study is to test whether the lower-extremity kinematics and strength, using the single-leg squat (SLS) and the countermovement jump (CMJ), are potential risk factors for lower-extremity injuries in preprofessional contemporary dancers. 


\section{METHODS}

\section{Study Design}

A prospective cohort was set up among first-year students of Codarts University of The Arts, Rotterdam, the Netherlands. The participants were full-time students in a Bachelor degree in Dance and Bachelor degree in Dance Teacher. Inclusion in the study was regardless of a previous lower-extremity injury. Only students who were injured at baseline and not able to perform the physical tests were excluded from the study. Ethical approval was given by the Medical Ethics Review Committee of the Academic Medical Centre Amsterdam, the Netherlands (W15_200). Written informed consent was obtained from all participating students.

\section{Procedures and Measurements}

Baseline measurements were conducted at the start of the academic year (2015/2016) and consisted of an intake questionnaire, physical examination, and physical performance tests. The intake questionnaire included items on age (years), sex, and injury history. In accordance with the Fuller consensus statement, injury history was defined as any physical complaint (only lower extremity) resulting in a fulltime loss of dance activities (participation in class, rehearsal, performance practice, etc.) for at least 1 week beyond the day of onset in the past year. ${ }^{20-22}$ During the physical examination, height and weight were measured with which body mass index (BMI) was calculated. The physical performance tests consisted of the SLS and the CMJ to measure lower-extremity kinematics and strength. ${ }^{23-25}$ During the following academic year (September 2015 to June 2016), injuries were recorded by means of a monthly questionnaire that included the Oslo Sports Trauma Research Center (OSTRC) Questionnaire on Health Problems. ${ }^{26}$ A reminder was sent to all students who did not respond on the questionnaire after 1 week.

\section{Physical Performance Tests}

The SLS was used to evaluate the dynamic position of the knee and shows a good interrater, intrarater and test-retest reliability. ${ }^{12,24,23}$ The SLS was performed following the guidelines of Stensrud et al. ${ }^{27}$ All students practiced the test 3 times with each leg with the researcher controlling the 90 degrees knee flexion with a goniometer. Markers were placed on the preacromion, manubrium sterni, Spina Iliaca Anterior Superior (SIAS), trochanter major, lateral and medial epicondyle of the knees, and lateral and medial malleoli of ankles. As starting position, students stood straight up and placed their arms across the chest. Movement was recorded on video in the frontal and sagittal plane using IPads. Students were instructed to squat until a knee flexion of 90 degrees was reached. The trial was not valid if the nonweight bearing leg touched the ground or if the student fell. ${ }^{27}$ The SLS was performed 3 times on each leg, and all students started on their left leg.

The frontal and sagittal videos of SLS were analyzed using Kinovea (Kinovea, version 0.08.15) by measuring the following angles on the first frame of peak knee flexion: hip flexion (HF), knee flexion (KF), ankle dorsiflexion (DAF), knee valgus (KV), lateral trunk motion (LTM), and pelvic tilt (PT). HF was defined as the angle between the line formed by pre-acromion and trochanter major and the line between the lateral knee epicondyle and trochanter major. KF was defined as the angle between the line formed by trochanter major and lateral epicondyle and the line between lateral knee epicondyle and lateral malleolus. DAF was the angle between the line formed by lateral epicondyle and calcaneus through lateral malleolus and the line between the fifth toe and calcaneus, with a larger dorsiflexion indicating limited ankle dorsiflexion. PT was the angle between the line formed by ipsilateral and contralateral SIAS and the horizontal line starting in the ipsilateral SIAS. The KV and LTM were measured accordingly to Dingenen et al. ${ }^{28}$ The average angle of 3 trials was calculated for both legs separately.

The CMJ test was used as a measure for strength of the lower extremity, and shows a good interrater, intrarater and test-retest reliability. ${ }^{23,29}$ Students were instructed to stand on the electronic timing plate (Fusion Sport, Chigaco, Illinois) with their hands on the hips. The plate detects flight time and converts this in jump height $(\mathrm{cm})$. Students were instructed to squat as deep as preferred and consequently jump as high as possible without flexion of the knees during the jump or removing the hands from the hips. The trial was rejected if an arm swing or knee bending occurred or if the student fell or lost balance while performing the CMJ. Students were instructed to land on the plate at exactly the same place as the starting point. The CMJ test was performed 3 times for jumping with both legs, and 3 times on the left and right leg separately. ${ }^{30}$ Consequently, the average jump height of these 3 trails from the different jumping tasks was computed.

Before the physical performance tests the students performed a standardized warming-up consisting of bipodal squats $(2 \times 8$ repetitions), bipodal jumps $(2 \times 5$ repetitions $)$, and stretching of the calf muscle with straight and bended knees. ${ }^{27}$

\section{Injury Registration}

The monthly questionnaire consisted of 4 key questions on the consequences of health problems on participation, training volume, and performance as well as the degree to which the student perceived symptoms (OSTRC Questionnaire on Health Problems). Each question of the OSTRC was scored with a 4- or 5-point scale, ranging from 0 (respectively: no problem, no reduction, no effect and no symptoms) to 25 (cannot participate at all or severe symptoms). The severity of a health problem was calculated on a scale of 0 (no health problem)-100 (cannot participate at all because of severe health problems) by summing the score of the 4 questions, according to the method proposed by Clarsen et al. ${ }^{31,32}$ If the severity score was 0 , the questionnaire was finished for that month. However, if a symptom was reported, the students were asked whether they referred to a physical injury, mental problem, or an illness. For physical injuries, the student was automatically directed to an injury registration form based on an international consensus statement on injury surveillance methodology for football to collect further details (eg, location, history, and acute or overuse onset). ${ }^{20,33-35}$

Lower-extremity injuries are defined as injuries at the lower back, pelvis, leg, knee, and foot. Students were defined to be substantial injured at their lower extremity if they reported problems leading to moderate or severe reductions (value $\geq 13$ on question 2 or 3 of the OSTRC) in training volume, or moderate or severe reductions in performance or complete 
inability to participate in dance at least once during followup. ${ }^{26}$

\section{Statistical Methods}

Statistical analyses were conducted using SPSS (SPSS, V21.0) and statistical significance level was set at an alpha level $>0.05$. Descriptive statistics were used to describe baseline characteristics of all participants using mean values and standard deviation (SD) or number and percentages $(\%)$. The 1-year incidence of all lower-extremity injuries and substantial lower-extremity injuries was calculated by dividing the number of students who reported at least 1 lower-extremity injury during the academic year by the number of respondents.

To examine potential risk factors for lower-extremity injuries, univariate and multivariate regression models were applied on leg-level using generalized estimating equations (GEE), taking into account the association between 2 legs within 1 person. Potential risk factors included age (years), sex (male), BMI $\left(\mathrm{kg} / \mathrm{m}^{2}\right)$, educational program (Bachelor Dance Teacher vs Bachelor Dance), injury history in the previous year (only lower-extremity injuries), all measured angles from the SLS (degree), and jump height from the CMJ $(\mathrm{cm})$ for jumping with both legs and a single leg. First, univariate associations between the potential risk factors and the dichotomized outcome: substantially injured at the lower extremity during follow-up (yes/no) were assessed. Second, multivariate regression modeling using GEE was performed including all potential risk factors and the outcome of interest. The results of the regression analyses were expressed in odds ratios (ORs) with corresponding 95\% confidence interval [95\% confidence interval $(\mathrm{CI})]$.

\section{RESULTS}

\section{Participants}

All approached students $(n=45)$ agreed to participate and were consequently included in this study. Four of these did not perform the CMJ, and one student was not able to execute the SLS on the right leg. The cohort comprised 28 females $(62.2 \%)$, the mean age was 18.6 years (SD 1.1), mean BMI was $20.7 \mathrm{~kg} / \mathrm{m}^{2}$ (SD 1.6) and 17 students had a lowerextremity injury history $(37.8 \%)$. Twenty eight $(62 \%)$ were students enrolled in the Bachelor degree Dance and 17 (38\%) in the Bachelor Dance Teacher (Table 1). The monthly response rate of the follow-up questionnaires ranged from $88.9 \%$ up to $100 \%$.

\section{Injuries}

During the academic year, a total of $37(82.2 \%)$ students reported a lower-extremity injury of which $19(51.4 \%)$ were categorized as substantial. The monthly incidence of all lowerextremity injuries ranged from $14.5 \%$ to $28.0 \%$ and from $4.4 \%$ to $12.2 \%$ for substantial lower-extremity injuries (Figure 1).

\section{Risk Factors for Lower-Extremity Injuries}

The univariate analyses showed a significant association between a limited dorsiflexion of the ankle (OR 1.11; 95\% CI 1.02-1.20) and substantial lower-extremity injuries during

\begin{tabular}{|l|c|}
\hline \multicolumn{2}{|c|}{ TABLE 1. Participants Characteristics } \\
\hline & Total Population (N = 45) \\
\hline Sex (female) & $28(62.2 \%)$ \\
\hline Age (yr) & $18.6(1.1)$ \\
\hline BMI (kg/m²) & $20.7(1.6)$ \\
\hline Educational program & $28(62.2 \%)$ \\
\hline Bachelor Dance & $17(37.8 \%)$ \\
\hline Bachelor Dance Teacher & $17(37.8 \%)$ \\
\hline Injury history (yes) & \\
\hline Single leg squat & \\
\hline Knee flexion (degrees) & $124.7(9.9)$ \\
\hline Right leg & $119.1(8.4)$ \\
\hline Left leg & \\
\hline Pelvic tilt (degrees) & $2.0(3.9)$ \\
\hline Right leg & $0.5(3.7)$ \\
\hline Left leg & \\
\hline Lateral trunk motion (degrees) & $14.7(2.3)$ \\
\hline Right leg & $12.6(2.2)$ \\
\hline Left leg & \\
\hline Knee valgus (degrees) & $176.8(6.3)$ \\
\hline Right leg & $178.3(6.1)$ \\
\hline Left leg & \\
\hline Dorsiflexion ankle (degrees) & $59.1(4.6)$ \\
\hline Right leg & $61.2(5.2)$ \\
\hline Left leg & $151.3(10.7)$ \\
\hline Hip flexion (degrees) & $150.2(10.6)$ \\
\hline Right leg & \\
\hline Left leg & $14.4(6.8)$ \\
\hline Countermovement jump & \\
\hline DL (cm)* & \\
\hline Right, SL (cm)* & \\
\hline Left, SL (cm) ${ }^{\star}$ & \\
\hline $\begin{array}{l}\text { Data are presented as mean (SD) or } n \text { (\%). } \\
{ }^{*} \text { Missing data from 3 persons. } \\
\text { DL, double leg; SL, single leg. }\end{array}$ & \\
\hline & \\
\hline
\end{tabular}

follow-up (Table 2). None of the other tested variables were univariately associated with the outcome of interest. The multivariate analysis also showed a significant association between limited dorsiflexion of the ankle (OR 1.25; 95\% CI, 1.03-1.52) and the occurrence of substantial injuries. None of the other potential risk factors were associated with the outcome in the multivariate analysis.

\section{DISCUSSION}

This is the first prospective cohort study investigating risk factors for lower-extremity injuries among contemporary dance students. We found a 1-year incidence of lowerextremity injuries of $82.2 \%$. Of these, $51.4 \%$ were substantial injuries meaning that the students were not able to participate at all or had a moderate or severe reduction in training volume or performance because of a lower-extremity injury. Results of the multivariate analysis showed that students with a limited ankle dorsiflexion (OR 1.25; 95\% CI, 1.03-1.52) had a higher 


\section{Monthly incidence}

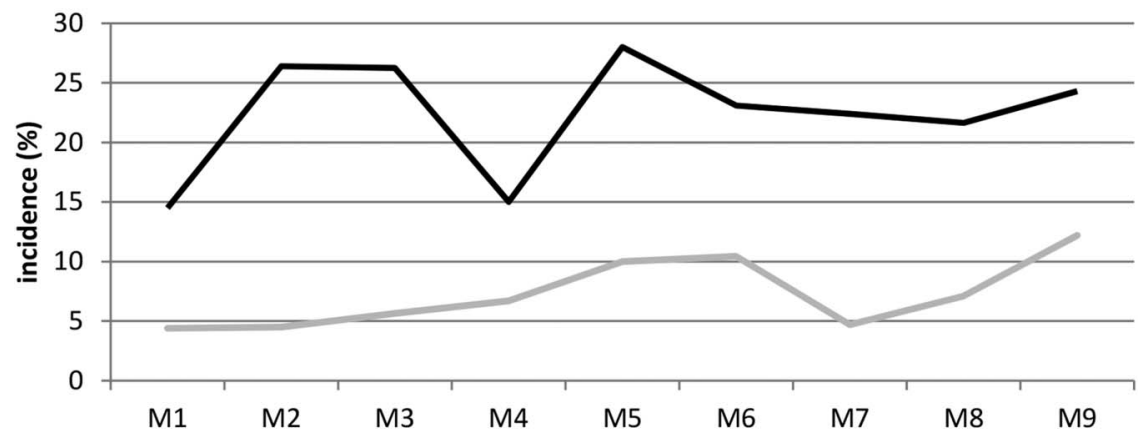

All lower extremity injuries —Substantial lower extremity injury
Figure 1. Monthly incidence of all and substantial lower-extremity injuries during the 9-month followup. risk of sustaining a substantial lower-extremity injury during the academic year.

The monthly incidence of all lower-extremity injuries ranged from $14.5 \%$ to $28.0 \%$ and from $4.4 \%$ to $12.2 \%$ for substantial lower-extremity injuries. In contrast to our findings, a retrospective cohort study of contemporary dance students found a 1-year incidence of lower-extremity injuries of $64 \% .^{8}$ Besides, injury incidence in professional contemporary dancers ranged from $24 \%$ to $74 \%$ in the literature. ${ }^{7,9,36}$ Differences in reported injury incidence may be due to differences in injury registration and associated injury definitions. Therefore, there is a need for oneuniversal injury case definition in dance medicine. ${ }^{6,37}$ Liederbach et al $^{38}$ made the first attempt for standardized testing and reporting methodology in dance medicine and science research. Their recommendation is to define an injury as an anatomic tissuelevel impairment diagnosed by a health care practitioner that results in full-time loss of activity for one or more days beyond the day of onset. However, this time-loss definition would be inadequate if the focus is on early detection. Therefore, the OSTC Overuse Injury Questionnaire as used in the current study seems to be a good instrument for this population, in addition to the recommendation of Liederbach et al (2012), as it registries all health problems (injuries, illness, and mental health problems) with standardized questions resulting in a summary severity score providing a measure of the impact of

\begin{tabular}{|c|c|c|c|c|}
\hline & $\begin{array}{c}\text { Noninjured } \\
(n=59 \text { Legs })\end{array}$ & $\begin{array}{c}\text { Injured } \\
\text { (n = } 31 \text { Legs) }\end{array}$ & $\begin{array}{l}\text { Univariate Analyses, } \\
\text { OR (95\% CI) }\end{array}$ & $\begin{array}{l}\text { Multivariate Analysis, } \\
\text { OR (95\% CI) }\end{array}$ \\
\hline \multicolumn{5}{|l|}{ Participant characteristics } \\
\hline Age (yr) & $18.5(0.97)$ & $18.7(1.30)$ & $1.18(0.67-2.09)$ & $0.78(0.44-1.41)$ \\
\hline Sex (male) & $18(30.5 \%)$ & $16(51.6 \%)$ & $2.43(0.76-7.73)$ & $0.56(0.03-10.88)$ \\
\hline Educational program (BA dance teacher) & $17(28.8 \%)$ & $17(54.8 \%)$ & $3.00(0.94-9.53)$ & $4.96(0.82-29.98)$ \\
\hline Injury history & $19(32.2 \%)$ & $15(48.4 \%)$ & $1.97(0.63-6.19)$ & $1.98(0.36-11.02)$ \\
\hline $\mathrm{BMI}\left(\mathrm{kg} / \mathrm{m}^{2}\right)$ & $20.4(1.65)$ & $21.2(1.38)$ & $1.41(0.95-2.09)$ & $1.02(0.68-1.53)$ \\
\hline \multicolumn{5}{|l|}{ Physical tests } \\
\hline \multicolumn{5}{|l|}{ Single-leg squat } \\
\hline Knee flexion (degrees) & $120.7(9.9)$ & $124.3(8.6)$ & $1.05(0.99-1.10)$ & $1.02(0.91-1.14)$ \\
\hline Pelvic tilt (degrees) & $1.1(3.7)$ & $1.6(4.3)$ & $1.03(0.93-1.15)$ & $0.99(0.86-1.15)$ \\
\hline Lateral trunk motion (degrees) & $13.6(2.5)$ & $13.6(2.5)$ & $1.02(0.94-1.09)$ & $1.07(0.93-1.23)$ \\
\hline Knee valgus (degrees) & $178.0(6.2)$ & $176.7(6.3)$ & $0.98(0.93-1.03)$ & $0.97(0.88-1.06)$ \\
\hline Dorsiflexion ankle (degrees) & $59.1(4.6)$ & $62.3(5.2)$ & $1.11(1.02-1.20)$ & $1.25(1.03-1.52)$ \\
\hline Hip flexion (degrees) & $151.7(10.1)$ & $148.9(11.5)$ & $0.99(0.94-1.04)$ & $0.99(0.91-1.06)$ \\
\hline \multicolumn{5}{|l|}{ Countermovement jump } \\
\hline Double leg (cm) & $30.9(6.4) \dagger$ & $32.5(7.4)^{\star}$ & $1.03(0.95-1.13)$ & $1.29(0.99-1.68)$ \\
\hline Single leg $(\mathrm{cm})$ & $14.5(3.9) \dagger$ & $13.7(3.5)^{\star}$ & $0.94(0.78-1.12)$ & $0.72(0.44-1.16)$ \\
\hline $\begin{array}{l}\text { Significant associations are indicated in bold. } \\
\text { * Missing data from } 2 \text { persons ( } 4 \text { legs). } \\
\text { + Missing data from } 1 \text { person ( } 2 \text { legs). }\end{array}$ & & & & \\
\hline
\end{tabular}


health problems. Using this questionnaire, we found injury rates higher than previously described in the literature.

To our knowledge, up to now no prospective studies have been performed to determine whether lower-extremity kinematics (SLS) and strength (CMJ) can predict lower-extremity injuries in contemporary dance students. The current study showed that limited ankle dorsiflexion was associated with a higher risk on lower-extremity injuries during the 9-month follow-up. None of the other potential risk factors measured with the SLS were associated with lower-extremity injuries. In other sport disciplines, prospective studies were performed to determine risk factors for injuries using functional tests. Bayne et $\mathrm{al}^{39}$ conducted a prospective injury study in cricket fast bowlers and found that an increased knee valgus angle during the single-leg decline squat was associated with a higher low back injury risk during the season. In elite Olympic class, sailors left-sided single-leg decline squat performance was associated with overall injury status, with better performing athletes recording fewer injuries. ${ }^{40}$ Furthermore some crosssectional studies have found significant associations between injury rates and SLS performances. ${ }^{17,41}$ However, because of the cross-sectional design of these studies, conclusions on causation cannot be drawn.

A limited dorsiflexion of the ankle in dance students might be due to a previous injury. From the literature, it is known that dancers with a history of lower-extremity injuries, including lateral ankle sprains, had significantly lower dorsiflexion measurements on the corresponding lower limbs (Wiesler et al). ${ }^{42}$ This might be due to an insufficient healing of the injury or changed structural and biomechanical characteristics of the ankle joint. This is supported by a MR imaging study in people with a 6 to 12 months earlier lateral ankle sprain in which was concluded that the prevalence of structural abnormalities (eg, bone marrow edema, lateral ligament lesions, fractures) was very high (van Putte-Katier et al). ${ }^{43}$ However, more research to the origin of limited dorsiflexion of the ankle in a population of dancers is needed.

The contribution of limited ankle dorsiflexion to accumulation of lower-extremity injuries remains unclear from the current study. From different studies it is known, for example, that in individuals with a history of ankle sprains and/or functional ankle instability a limited ankle dorsiflexion is associated with impaired balance. ${ }^{44,45}$ This indicates that changes in ankle motion may negatively influence dynamic postural control and may contribute to the occurrence of lower-extremity injuries. To unravel the influence of limited ankle dorsiflexion on sustaining lower-extremity injuries it is necessary to assess the association of ankle dorsiflexion with injuries of specific lower-extremity regions (eg, ankle, knee, or hip) or with specific lower-extremity injuries (eg, ankle sprain, PFP syndrome). More large-scale prospective studies are needed to gain insight into the association between limited ankle dorsiflexion and specific lower-extremity regions/ injuries.

The outcomes of the $\mathrm{CMJ}$ in this study were not associated with a higher risk on lower-extremity injuries. In contrast to our findings, Henry et $\mathrm{al}^{46}$ found that poorer lower limb power output measured with the vertical jump was associated with an increased risk of noncontact ankle injuries among amateur soccer players. Likewise, a retrospective study among police recruits found a significant correlation between vertical jump height and reported injuries. ${ }^{47}$ The difference in outcomes between our study and these latter studies could be due a different study population (dance students vs police recruits and soccer players) or a different outcome of interest (lower-extremity injuries vs ankle injuries and upper- and lower-extremity injuries).

It is notable that students enrolled in the Bachelor Dance Teacher showed generally higher ORs, although not significant, for sustaining a lower-extremity injury during the academic year compared with students enrolled in the Bachelor Dance. The fact that dance teacher students are possibly more susceptible for lower-extremity injuries may be due to differences in the structure of the educational program and/or their physical fitness. Because of the differences in the educational program, dance teacher students might be exposed to higher physical strain and have less time to recover from their training, rehearsals, and performances. Combined with a lower physical fitness makes a dance teacher student at higher risk for injuries. However, in the present study, the balance between exposure and recovery and physical fitness has not been measured. To understand why these students might be at higher risk for sustaining a lower-extremity injury more research is needed to get insight in the relation between exposure, recovery, and physical fitness.

\section{Strengths and Limits}

The major strength of the current study is the prospective study design with a monthly follow-up, resulting in low interference of recall bias. In addition, the response rate to the monthly questionnaires was high (89\% to $100 \%)$. Although it is recommended to register injuries on a weekly basis with the OSTC Overuse Injury Questionnaire, the frequency of injury registration once a month does not influence the average incidence and severity scores. ${ }^{26}$

However, there are some limitations. First, because of the small sample size ( $\mathrm{N}=45,90$ legs), it was not possible to adhere to the "rule of 10" (14 potential risk factors, 31 events), resulting in overfitting of the final model. ${ }^{48}$ This causes us to be cautious to draw firm conclusions. Second, all injuries were self-reported, which lead to a lack of detailed diagnostic information on each case. This limits us to distinguish between diagnoses of different lower-extremity injuries. Third, the knee flexion of the dance students while performing the SLS was on average 120.5 to 125.2 degree for the noninjured and injured leg, respectively. From the literature, it is known that a knee flexion of 75 to 90 degree is needed to differentiate between sexes. ${ }^{12,49,50}$ Therefore, it can be expected that the relatively small knee flexion was not sufficient to show relevant discrepancies in all measured angles to predict lower-extremity injuries. This might have influenced our study outcomes. Fourth, physical performance tests in dance are often adapted from precedents in sport and exercise. There are some studies describing the relevance of the SLS and CMJ in a population of dancers. However, more research is needed. ${ }^{18,51}$ Finally, Stensrud et $\mathrm{al}^{27}$ found that $50 \%$ of the participants with poor knee control were not detected when only 1 test, such as the SLS, would be used. Poor knee control was defined as having lateral tilt of the pelvis and/or moving the knee in valgus position and/or clear medial/lateral side-to-side movements of the knee. ${ }^{27}$ Because we may not have identified all students with poor knee control, it may have limited us in recording an association between the SLS and lower-extremity injuries in this population. Combining information from several tests may 
improve sensitivity identifying participants with poor knee control. However, in a recent critical review of $\mathrm{Bahr}^{52}$ it becomes clear that there is no screening test with adequate test properties to predict sports injuries and that evidence in support for screening injury risk is lacking. Therefore, screening tests to predict and prevent dance-related injuries should be developed according to the 3 steps proposed by Bahr. $^{52}$

\section{Implications for Future Research}

Although this is the first prospective cohort study investigating risk factors for lower-extremity injuries among contemporary dance students, more prospective research with larger sample sizes is needed. These studies will allow us to draw stronger conclusions about risk factors for lower-extremity injuries and compare different dance populations. Besides, it will enables us to identify risk factors for specific injuries. Insight in factors predicting substantial injuries enables us to enhance the prevention of dance-related injuries in the future by developing preventive strategies.

\section{CONCLUSIONS}

This study aimed to identify risk factors, that is lowerextremity kinematics and strength for lower-extremity injuries in contemporary dance students during the academic year. The results show that students with a limited ankle dorsiflexion during the SLS are at higher risk for lowerextremity injuries during the academic year. This finding provides us essential information to enhance the prevention of dance-related injuries. However, the results of this study are based on a small population; the conclusions should be interpreted with some caution. Therefore, further research is needed to gain more insight in risk factors for this high-risk population to develop preventive strategies.

\section{ACKNOWLEDGMENTS}

The authors would like to thank Angelo Richardson, Diana van Winden, Stephanie Keizer-Hulsebosch, and Suze Steemers for their help in administering the monthly questionnaires and their help during the physical performance tests.

\section{References}

1. Kenny SJ, Whittaker JL, Emery CA. Risk factors for musculoskeletal injury in preprofessional dancers: a systematic review. Br J Sports Med. 2016;50:997-1003.

2. Gamboa JM, Roberts La, Maring J, et al. Injury patterns in elite preprofessional ballet dancers and the utility of screening programs to identify risk characteristics. J Orthop Sports Phys Ther. 2008;38: 126-136.

3. Ekegren CL, Quested R, Brodrick A. Injuries in pre-professional ballet dancers: incidence, characteristics and consequences. J Sci Med Sport. 2014;17:271-275.

4. Luke AC, Kinney SA, D'Hemecourt PA, et al. Determinants of injuries in young dancers. Med Probl Perform Art. 2002;17:105-112.

5. Weigert BJ, Erickson M. Incidence of injuries in female university-level modern dancers and the effectiveness of a screening program in altering injury patterns. Med Probl Perform Art. 2007;22:52-57.

6. Hincapié CA, Morton EJ, Cassidy JD. Musculoskeletal injuries and pain in dancers: a systematic review. Arch Phys Med Rehabil. 2008;89: 1819-1829.

7. Campoy FAS, Coelho LRDO, Bastos FN, et al. Investigation of risk factors and characteristics of dance injuries. Clin J Sport Med. 2011; 21:493-498.
8. Baker J, Scott D, Watkins K, et al. Self-reported and reported injury patterns in contemporary dance students. Med Probl Perform Art. 2010; 25:10-15.

9. Shah S, Weiss DS, Burchette RJ. Injuries in professional modern dancers: incidence, risk factors, and management. J Dance Med Sci. 2012;16: 17-25.

10. Echegoyen S, Acuña E, Rodríguez C. Injuries in students of three different dance techniques. Med Probl Perform Art. 2010;25:72-74.

11. Anand Prakash A. Medical attention seeking dance injuries: systematic review of case reports. Phys Sport. 2017;45:64-74.

12. Zeller BL, McCrory JL, Kibler WB, et al. Differences in kinematics and electromyographic activity between men and women during the singlelegged squat. Am J Sport Med. 2003;31:449-456.

13. Myer GD, Ford KR, Barber Foss KD, et al. The incidence and potential pathomechanics of patellofemoral pain in female athletes. Clin Biomech. 2010;25:700-707.

14. Myer G, Ford K, Di Stasi S, et al. High knee abduction moments are common risk factors for patellofemoral pain (PFP) and anterior cruciate ligament (ACL) injury in girls: is PFP itself a predictor for subsequent ACL injury? Br J Sports Med. 2015;49:118-122.

15. Hewett TE, Myer GD, Ford KR, et al. Biomechanical measures of neuromuscular control and valgus loading of the knee predict anterior cruciate ligament injury risk in female athletes: a prospective study. Am J Sports Med. 2005;33:492-501.

16. Herrington L. Knee valgus angle during single leg squat and landing in patellofemoral pain patients and controls. Knee. 2014;21:514-517.

17. Nakagawa TH, Maciel CD, Serrão FV. Trunk biomechanics and its association with hip and knee kinematics in patients with and without patellofemoral pain. Man Ther. 2015;20:189-193.

18. Angioi M, Metsios GS, Koutedakis Y, et al. Physical fitness and severity of injuries in contemporary dance. Med Probl Perform Art. 2009;24:26-29.

19. Koutedakis Y, Khaloula M, Pacy PJ, et al. Thigh peak torques and lowerbody injuries in dancers. J Danc Med Sci. 1997;1:12-15.

20. Fuller CW, Ekstrand J, Junge A, et al. Consensus statement on injury definitions and data collection procedures in studies of football (soccer) injuries. Scand J Med Sci Sport. 2006;16:83-92.

21. van Beijsterveldt AM, Stubbe JH, Schmikli SL, et al. Differences in injury risk and characteristics between Dutch amateur and professional soccer players. J Sci Med Sport. 2015;18:145-149.

22. Bliekendaal S, Goossens L, Stubbe JH. Incidence and risk factors of injuries and their impact on academic success: a prospective study in PETE students. Scand J Med Sci Sports. 2017;27:1978-1985.

23. Markovic G, Dizdar D, Jukic I, et al. Reliability and factorial validity of squat and countermovement jump tests. J Strength Cond Res. 2004;18: 551-555.

24. Weeks BK, Carty CP, Horan SA. Kinematic predictors of single-leg squat performance: a comparison of experienced physiotherapists and student physiotherapists. BMC Musculoskelet Disord. 2012;13:207.

25. Whatman C, Hume P, Hing W. Kinematics during lower extremity functional screening tests in young athletes-are they reliable and valid? Phys Ther Sport. 2013;14:87-93.

26. Clarsen B, Myklebust G, Bahr R. Development and validation of a new method for the registration of overuse injuries in sports injury epidemiology: the Oslo Sports Trauma Research Centre (OSTRC) overuse injury questionnaire. Br J Sports Med. 2013;47:495-502.

27. Stensrud S, Myklebust G, Kristianslund E, et al. Correlation between twodimensional video analysis and subjective assessment in evaluating knee control among elite female team handball players. Br J Sports Med. 2011; 45:589-595.

28. Dingenen B, Malfait B, Vanrenterghem J, et al. The reliability and validity of the measurement of lateral trunk motion in two-dimensional video analysis during unipodal functional screening tests in elite female athletes. Phys Ther Sport. 2014;15:117-123.

29. Cormack SJ, Newton RU, McGulgan MR, et al. Reliability of measures obtained during single and repeated countermovement jumps. Int J Sports Physiol Perform. 2008;3:131-144.

30. Vescovi JD, VanHeest JL. Effects of an anterior cruciate ligament injury prevention program on performance in adolescent female soccer players. Scand J Med Sci Sport. 2010;20:394-402.

31. Clarsen B, Rønsen O, Myklebust G, et al. The Oslo Sports Trauma Research Center questionnaire on health problems: a new approach to prospective monitoring of illness and injury in elite athletes. $\mathrm{Br} J$ Sports Med. 2014;48:754-760.

32. Pluim BM, Loeffen FGJ, Clarsen B, et al. A one-season prospective study of injuries and illness in elite junior tennis. Scand J Med Sci Sport. 2016;26: 564-571. 
33. Pluim BM, Fuller CW, Batt ME, et al. Consensus statement on epidemiological studies of medical conditions in tennis. Br J Sports Med. 2009;43:893-897.

34. Fuller CW, Bahr R, Dick RW, et al. A framework for recording recurrences, reinjuries, and exacerbations in injury surveillance. Clin J Sport Med. 2007;17:197-200.

35. Fuller C, Molloy M, Bagate C, et al. Consensus statement on injury definitions and data collection procedures for studies of injuries in rugby union. Br J Sports Med. 2007;41:328-331.

36. Jacobs CL, Cassidy JD, Cote P, et al. Musculoskeletal injury in professional dancers: prevalence and associated factors: an international cross-sectional study. Clin J Sport Med. 2017;27:153-160.

37. Smith PJ, Gerrie BJ, Varner KE, et al. Incidence and prevalence of musculoskeletal injury in ballet: a systematic review. Orthop J Sport Med. 2015;3:2325967115592621.

38. Liederbach M, Hagins M, Gamboa JM, et al. Assessing and reporting dancer capacities, risk factors, and injuries: recommendations from the IADMS standard measures consensus initiative. J Dance Med Sci. 2012; 16:139-153.

39. Bayne H, Elliott B, Campbell A, et al. Lumbar load in adolescent fast bowlers: a prospective injury study. J Sci Med Sport. 2016;19:117-122.

40. Schultz AB, Taaffe DR, Blackburn M, et al. Musculoskeletal screening as a predictor of seasonal injury in elite Olympic class sailors. J Sci Med Sport. 2016;19:903-909.

41. Yamazaki J, Muneta T, Ju YJ, et al. Differences in kinematics of single leg squatting between anterior cruciate ligament-injured patients and healthy controls. Knee Surg Sports Traumatol Arthrosc. 2010;18:56-63.

42. Wiesler ER, Hunter DM, Martin DF, et al. Ankle flexibility and injury patterns in dancers. Am J Sports Med. 1996;24:754-757.
43. van Putte-Katier N, van Ochten JM, van Middelkoop M, et al. Magnetic resonance imaging abnormalities after lateral ankle trauma in injured and contralateral ankles. Eur J Radiol. 2015;84:2586-2592.

44. Hoch MC, Staton GS, Medina McKeon JM, et al. Dorsiflexion and dynamic postural control deficits are present in those with chronic ankle instability. J Sci Med Sport. 2012;15:574-579.

45. Terada M, Harkey MS, Wells AM, et al. The influence of ankle dorsiflexion and self-reported patient outcomes on dynamic postural control in participants with chronic ankle instability. Gait Posture. 2014; 40:193-197.

46. Henry T, Evans K, Snodgrass SJ, et al. Risk factors for noncontact ankle injuries in amateur male soccer players: a prospective cohort study. Clin J Sport Med. 2016;26:251-258.

47. Orr R, Pope R, Peterson S, et al. Leg power as an indicator of risk of injury or illness in police recruits. Int J Environ Res Public Health 2016;13:237.

48. Peduzzi P, Concato J, Kemper E, et al. A simulation study of the number of events per variable in logistic regression analysis. J Clin Epidemiol. 1996; 49:1373-1379.

49. Graci V, Van Dillen LR, Salsich GB. Gender differences in trunk, pelvis and lower limb kinematics during a single leg squat. Gait Posture. 2012; 36:461-466.

50. Claiborne TL, Armstrong CW, Gandhi V, et al. Relationship between hip and knee strength and knee valgus during a single leg squat. $J A p p l$ Biomech. 2006;22:41-50.

51. Hopper LS, Sato N, Weidemann AL. Single-leg squats can predict leg alignment in dancers performing ballet movements in "turnout". Open Access J Sports Med. 2016;7:161-166.

52. Bahr R. Why screening tests to predict injury do not work-and probably never will...: a critical review. Br J Sports Med. 2016;50:776-780. 